\title{
A simple technique for the detection of anti-malarial drug formulations and their presence in human urine
}

\author{
L. LUGIMBANA ${ }^{*}$, H.M. MALEBO ${ }^{1}$, M.D. SEGEJA², J.A. AKIDA², L.N. MALLE² and M.M. LEMNGE² \\ ${ }^{1}$ National Institute for Medical Research, P.O. Box 9653, Dar es Salaam, Tanzania \\ ${ }^{2}$ Tanga Medical Research Centre, P.O. Box 5004, Tanga, Tanzania
}

\begin{abstract}
A simple, sensitive, specific assay technique for the detection and semi-quantification of chloroquine, amodiaquine, quinine, primaquine, sulfadoxine and pyrimethamine in formulations and in human urine by using thin layer chromatography (TLC) was developed and tested in the laboratory. The method involved developing test samples spotted on TLC chromatogram by diethylamine-toluene-isopropanol (1:4:5 v/v/v) as the eluting solvent. The solvent system diethylamine-toluene-isopropanol $(1: 4: 5 \mathrm{v} / \mathrm{v} / \mathrm{v})$ enabled the elution and detection of all the tested antimalarial drugs in solution and those spiked in human urine. Detection limits for chloroquine, amodiaquine, quinine and primaquine were the lowest at $0.00025 \mathrm{mg} / \mathrm{ml}$. Sulfadoxine exhibited a detection limit of $0.0005 \mathrm{mg} / \mathrm{ml}$ whereas that of pyrimethamine was $0.001 \mathrm{mg} / \mathrm{ml}$. The results indicate the suitability of this technique in antimalarial drug quality and bioavailability studies. It is envisaged that this technique will adequately address the role of drug absorption and excretion in the chemotherapy of malaria as well as to detect types of antimalarial drugs commonly used in the community.
\end{abstract}

Key words: TLC, bioassay, bioavailability, anti-malarial drugs, urine

\section{Introduction}

Malaria continues to be a major public health concern in Africa, South East Asia and Latin America. The latest World Health Organization data indicate that, over 2.4 billion people in more than 100 countries are exposed to the risk of malaria, whereas about 300 - 500 million of them suffer from malaria each year and more than one million die in Africa alone each year (WHO, 2003; Hay et al., 2004). Due to the increased mobility of people, the malaria risk is increasing. In sub-Saharan Africa, the threat of malaria is exacerbated by increasing resistance and the free flow of counterfeit and substandard antimalarial drugs (Stenson et al., 1998; Rimoy et al., 2002,). Among the known causes of resistance is the use of inadequate dosage either due to ignorance or poor quality drugs. Poor-quality antimalarial drugs have been widely reported in Africa, Asia and Latin America (Shakoor et al., 1997, Stenson et al., 1998; Rimoy et al., 2002; Idowu et al., 2006). Antimalarial drugs with incorrect amounts of active ingredients as well as drugs lacking active ingredient (s) have already been reported ( $\mathrm{Li}$ Wan Po, 2001). Poor quality and counterfeit drugs are not uncommon in Tanzania and other parts of subSaharan Africa (Rimoy et al., 2002, Ogwal-Okeng et al., 1998).

The use of counterfeit or substandard antimalarial drugs results to treatment failures, toxicity or sideeffects and it is among the major reasons for the development of antimalarial drug resistance (Stenson et al., 1998; Shakoor et al., 1997; Li Wan Po, 2001; Minzi et al., 2003). The availability of good quality antimalarial drugs is important for the effective treatment and control of malaria.

At the moment there is no cheap, simple and reliable analytical method available, which can be used to follow up the history of people undergoing a treatment as well as to identify counterfeit and substandard antimalarial drugs in circulation. Furthermore, there is no single simple semiquantitative method, which can be used to detect more than one antimalarial drug using the same test system and conditions. This means, there is a shortage of simple and convenient analytical methods for monitoring antimalarial drug quality, usage, adequate absorption, and excretion. To bridge the existing gap in science, we have developed a cheap and simple TLC method that meets the criteria for screening specificity, rapidity, sensitivity and simplicity-of antimalaria drugs.

\section{Materials and Methods}

Preparation of standard solutions and study samples Dragendorff reagent was prepared by mixing $1.3 \mathrm{~g}$ of bismuth subnitrate in $60 \mathrm{ml}$ of water and $15 \mathrm{ml}$ of glacial acetic acid to $12 \mathrm{~g}$ potassium iodide in $30 \mathrm{ml}$ of water. The mixture was diluted with $100 \mathrm{ml}$ of water and $25 \mathrm{ml}$ of glacial acetic acid. P-anisaldehydyde spray reagent was prepared by mixing $95 \mathrm{ml}$ of ethanol, $5 \mathrm{ml}$ of 4 methoxybenzaldehyde, $5 \mathrm{ml}$ of glacial acetic acid and $5 \mathrm{ml}$ of concentrated sulphuric acid. Methanolic- $\mathrm{H}_{2} \mathrm{SO}_{4}$ reagent was prepared by mixing $95 \mathrm{ml}$ of methanol with $5 \mathrm{ml}$ of concentrated sulphuric acid. 
To prepare a standard solution, an accurately weighed amount of chloroquine, amodiaquine, quinine, sulphadoxine and pyrimethamine were dissolved in $1 \mathrm{ml}$ of DMSO each aliquot corresponding to $10,8,6,5,4,3,2,1,0.5,0.25,0.1$, $0.05,0.025,0.001,0.0005,0.00025$ and $0.000125 \mathrm{mg} /$ $\mathrm{ml}$ of a standard solution, respectively and stored at $4^{0} \mathrm{C}$ until analysis. These standards were then used for comparisons in all experiments.

The study samples were obtained by taking an aliquot from the $10 \mathrm{mg} / \mathrm{ml}$ standard solution of chloroquine, amodiaquine, quinine, sulphadoxine and pyrimethamine. Drug-free blank urine were used for the serially dilution of standard drugs to yield test concentrations corresponding to 10,8, 6, 5, 4, 3, 2, 1, $0.5,0.25,0.1,0.05,0.025,0.001,0.0005,0.00025$ and $0.000125 \mathrm{mg} / \mathrm{ml}$ and these were used to develop for detection and in a semi-quantitative concentration scale for the antimalarial drugs in urine.

Accurately weighed amount of chloroquine, amodiaquine, quinine, sulphadoxine and pyrimethamine were then diluted with pre-tested blank human urine to obtain the quality control (QC) samples as standard aliquots containing $10,8,6,5,4$, $3,2,1,0.5,0.25,0.1,0.05,0.025,0.001,0.0005$, 0.00025 and $0.000125 \mathrm{mg} / \mathrm{ml}$, and stored at $4^{\circ} \mathrm{C}$ until analysis. Human urine from a healthy volunteer was collected in a $40 \mathrm{~mL}$ sample vials and stored at $4^{\circ} \mathrm{C}$ until analysis.

\section{Preparation of thin-layer chromatogram}

The TLC plates were marked with dots $10 \mathrm{~mm}$ from the edge; the dots were spotted $20 \mathrm{~mm}$ apart. $10 \mu \mathrm{l}$ of each of the test urine was applied in the dots. Five standards with lower concentrations: $0.025,0.001$, $0.0005,0.00025$ and $0.000125 \mathrm{mg} / \mathrm{ml}$ were applied prior to the test samples, and when the test samples showed higher concentration, the test was repeated with higher concentration standards viz, 10, 8, 6, 5, $4,3,2,1,0.5,0.25,0.1,0.05, \mathrm{mg} / \mathrm{ml}$. The spots were allowed to dry in air.

The TLC developing tank was placed by its base and $50 \mathrm{ml}$ exactly of the developing solvent systems were poured in the tank. TLC developing solvent systems were used to develop the chromatograms, allowing the solvent front to migrate about $10 \mathrm{~cm}$. The TLC plates were either sprayed with $\mathrm{AlCl}_{3} 20 \%$ in ethanol before visualization in a $254 \mathrm{~nm}$ and $366 \mathrm{~nm}$ short and long wavelength so as to have a very sensitive colour differentiation of the spots or immersed in a 2:3 paraffin: n-hexane solution to preserve the fluorescence. After visualization, the TLC plates were sprayed with different spray reagents for better conclusion of the detected spots. Retention factor (Rf) values for the unconverted drugs and their $\mathrm{Rf}$ metabolites were calculated using the formula:

\section{$R f=$ Distance moved by the solute Distance covered by the mobile phase}

Semi-quantitation was done by comparing the spot of the test sample with those of standard solutions. After detection, two neighbouring standard spots bracketing a sample spot was used for the estimation.

\section{Results}

The semi-quantitative TLC method was developed for the detection and estimation of the concentration of chloroquine, amodiaquine, quinine, primaquine, sulfadoxine and pyrimethamine. A variety of solvents were tested for their abilities to elute and separate the antimalarial drugs in a normal phase silica gel 60 TLC plate (Table 1). Chloroquine, amodiaquine, quinine and primaquine were easily eluted and detected in all mid and polar solvent systems. Sulfadoxine and pyrimethamine proved to be very polar and were not detected in all the mid and polar solvent systems tested with only exception being the very polar solvent system with a triple combination: diethylaminetoluene-isopropanol $(1: 4: 5 \mathrm{v} / \mathrm{v} / \mathrm{v})$. The solvent system diethylamine-toluene-isopropanol $(1: 4: 5 \mathrm{v} / \mathrm{v} / \mathrm{v})$ enabled the elution and the detection of all the tested antimalarial drugs in the same TLC plate. 
Table 1: Solvent system for chloroquine (CQ), amodiaquine (AQ), primaquine (PQ), quinine (QN), sulfadoxine (SD) and pyrimethamine (PR)

\begin{tabular}{|c|c|c|c|c|c|c|c|}
\hline Solvent system & $\begin{array}{l}\text { Ratio } \\
\text { (v/v/v) }\end{array}$ & $\mathbf{C Q}$ & $A Q$ & QN & $P Q$ & SD & PR \\
\hline Methanol-water & $1: 1$ & + & + & + & + & - & - \\
\hline Dichloromethane-methanol & $3: 1$ & + & + & + & + & - & - \\
\hline Dichloromethane-methanol & $9: 1$ & + & + & + & + & - & - \\
\hline Dichloromethane-ethanol & $2: 1$ & + & + & + & + & - & - \\
\hline Ethylacetate-n-hexane & $1: 1$ & + & + & + & + & - & - \\
\hline Toluene-diethylamine-methanol & $8: 1: 1$ & + & + & + & + & - & - \\
\hline Diethylamnie-methanol-water & $9: 0.5: 0.5$ & + & + & + & + & - & - \\
\hline Chloroform-acetone-isopropanol & $8: 1: 1$ & + & + & + & + & - & - \\
\hline Diethylamine-toluene-isopropanol & $1: 4: 5$ & + & + & + & + & + & + \\
\hline Toluene-isopropanol-dimethylformamide & 5.5:3.0:1.5 & + & + & + & + & - & - \\
\hline Methanol-isopropanol-dimethylformamide & 5.5:3.0:1.5 & + & + & + & + & 一 & 一 \\
\hline
\end{tabular}

Key: + = eluted, - = not eluted

During the development of the TLC method it was observed that a pre-saturation of the TLC chamber with mobile phase for at least $10 \mathrm{~min}$ was required to obtain a good separation with reproducible retention factor (Rf) values. Primary analysis of the mobility and detection of the drugs was made based on their sensitivity pattern on UV/VIS light at 254 and 366 $\mathrm{nm}$ wavelength. The drugs were found to exhibit different retention factors, UV/VIS spots at 254 and $366 \mathrm{~nm}$ wavelengths and different colour reactions when sprayed with $p$-anisaldehyde, dragendorff or methanolic sulphuric acid (Table 2).

Scheme for the detection and confirmation of the presence of chloroquine $(\mathrm{Rf}=0.88)$, amodiaquine $(\mathrm{Rf}=0.90)$, quinine $(\mathrm{Rf}=0.77)$, primaquine $(\mathrm{Rf}=$ $0.69)$, sulfadoxine $(R f=0.27)$ and pyrimethamine $(R f$

$=0.81$, in the test system was done by running dragendorff or methanolic sulphuric acid provided characteristic coloured spot at respective Rf values corresponding to pure chloroquine, amodiaquine, quinine, primaquine, sulfadoxine and pyrimethamine respectively; which confirmed and differentiated the tested antimalarials according to their chemical species, indicating the method is accurate and specific.

Semi-quantitation was done by comparing intensities of the test TLC UV/VIS spots with those of standard solutions and quality control samples with respect to their $\mathrm{Rf}$ and spray reagents colour reactions. The detection limit was measured as the lowest concentration resulting to the lowest observable TLC UV/VIS spots. According to this rule, the values of the detection limits of chloroquine, amodiaquine, quinine and primaquine were the lowest at 0.00025 $\mathrm{mg} / \mathrm{ml}$. Sulfadoxine exhibited a detection limit of

Table 2: UV visibility, retention factors and colour reaction of chloroquine (CQ), amodiaquine (AQ), primaquine (PQ), quinine (QN), sulfadoxine (SD) and pyrimethamine (PR) with spray reagents

\begin{tabular}{|c|c|c|c|c|c|c|}
\hline & $\mathbf{C Q}$ & $A Q$ & QN & $P Q$ & SD & PR \\
\hline $\begin{array}{l}\text { Reaction Factor } \\
\text { Visibility of spot under UV }\end{array}$ & 0.88 & 0.90 & 0.77 & 0.69 & 0.27 & 0.81 \\
\hline $254 \mathrm{~nm}$ & Blue & Black & Deep blue & Black & Deep blue & Deep blue \\
\hline $366 \mathrm{~nm}$ & Light blue & Yellow & Light blue & Yellow & None & None \\
\hline \multicolumn{7}{|l|}{$\begin{array}{l}\text { Colour reaction with spray } \\
\text { reagents }\end{array}$} \\
\hline P-anisaldehyde & No reaction & Yellow & No reaction & Yellow & Yellow & No reaction \\
\hline Dragendorff & Brown & Orange & Yellow & Orange & Yellow & Brownish \\
\hline Methanolic- $\mathrm{H}_{2} \mathrm{SO}_{4}$ & No reaction & Yellow & No reaction & Yellow & No reaction & No reaction \\
\hline
\end{tabular}

samples serially diluted down a level which could not be detected. Further tests on the study samples in comparison to the quality control samples of chloroquine, amodiaquine, quinine, primaquine, sulfadoxine and pyrimethamine successfully gave similar results confirming the detection of the presence of the antimalarial drugs. Spraying of the TLC chromatograms with $p$-anisaldehyde,
$0.0005 \mathrm{mg} / \mathrm{ml}$ where as that of pyrimethamine was $0.001 \mathrm{mg} / \mathrm{ml}$ (Table 3). Such results were reproducible in the comparison of the test samples, standard solutions and the quality control samples. It was observed that, the variation of the test samples, standard solutions and the quality control samples precision was very negligible, comparable and within the limits. 
Table 3: Detection limits based on UV/VIS absorptions of chloroquine (CQ), amodiaquine (AQ), primaquine (PQ), quinine (QN), sulfadoxine (SD) and pyrimethamine (PR) diluted with human urine using solvent system diethylamine-toluene-isopropanol $1: 4: 5 \mathrm{v} / \mathrm{v} / \mathrm{v}$

\begin{tabular}{|c|c|c|c|c|c|c|c|c|c|c|c|c|}
\hline \multirow{2}{*}{$\begin{array}{l}\text { Conc. } \\
\text { (mg/ml) }\end{array}$} & \multicolumn{2}{|c|}{$C Q$} & \multicolumn{2}{|c|}{$A Q$} & \multicolumn{2}{|c|}{ QN } & \multicolumn{2}{|c|}{$P Q$} & \multicolumn{2}{|c|}{ SD } & \multicolumn{2}{|c|}{ PR } \\
\hline & $254 \mathrm{~nm}$ & $366 \mathrm{~nm}$ & $254 \mathrm{~nm}$ & $366 \mathrm{~nm}$ & $254 \mathrm{~nm}$ & $366 \mathrm{~nm}$ & $254 \mathrm{~nm}$ & $366 \mathrm{~nm}$ & $254 \mathrm{~nm}$ & $366 \mathrm{~nm}$ & $254 \mathrm{Nm}$ & $366 \mathrm{~nm}$ \\
\hline 10 & ++++ & ++++ & ++++ & ++++ & ++++ & ++++ & ++++ & ++++ & ++++ & - & ++++ & - \\
\hline 8 & ++++ & ++++ & ++++ & ++++ & ++++ & ++++ & ++++ & ++++ & ++++ & - & ++++ & - \\
\hline 6 & ++++ & ++++ & ++++ & ++++ & ++++ & ++++ & ++++ & ++++ & ++++ & - & ++++ & - \\
\hline 5 & ++++ & ++++ & ++++ & ++++ & ++++ & ++++ & ++++ & ++++ & ++++ & - & ++++ & - \\
\hline 4 & ++++ & ++++ & ++++ & ++++ & ++++ & ++++ & ++++ & ++++ & ++++ & - & ++++ & - \\
\hline 3 & +++ & +++ & +++ & +++ & +++ & +++ & +++ & +++ & +++ & - & +++ & - \\
\hline 2 & +++ & +++ & +++ & +++ & +++ & +++ & +++ & +++ & +++ & - & +++ & - \\
\hline 1 & +++ & +++ & +++ & +++ & +++ & +++ & +++ & +++ & +++ & - & +++ & - \\
\hline 0.5 & ++ & ++ & ++ & ++ & ++ & ++ & ++ & ++ & ++ & - & ++ & - \\
\hline 0.25 & ++ & ++ & ++ & ++ & ++ & ++ & ++ & ++ & ++ & - & ++ & - \\
\hline 0.1 & + & + & + & + & + & + & + & + & + & - & + & - \\
\hline 0.05 & + & + & + & + & + & + & + & + & + & - & + & - \\
\hline 0.025 & + & + & + & + & + & + & + & + & + & - & + & - \\
\hline 0.001 & \pm & \pm & \pm & \pm & \pm & \pm & \pm & \pm & \pm & - & \pm & - \\
\hline 0.0005 & \pm & \pm & \pm & \pm & \pm & \pm & \pm & \pm & \pm & - & - & - \\
\hline 0.00025 & \pm & \pm & \pm & \pm & \pm & \pm & \pm & \pm & - & - & - & - \\
\hline 0.000125 & - & - & - & - & - & - & - & - & - & - & - & - \\
\hline
\end{tabular}

Key: $++++=$ very strong; $+++=$ strong; $++=$ moderate; $+=$ weak; $\pm=$ very weak; $-=$ not detectable

\section{Discussion}

A number of assay methods have been developed for detection and quantification of drugs in biological fluids, but many of them suffer from time consuming (Pokrajac \& Varagic, 1983), method specificity to certain drugs and/or expensive assay procedures (Desage et al., 1984; Devarajan et al., 1999). At the moment, there is no method with a single solvent system which can be used to identify all the antimalarials in clinical use. Such use of a combination of detection methods is a limitation to large scale field studies. Several qualitative methods have been developed for detection of chloroquine in urine tests (Brodie et al., 1947; Wilson \& Edeson, 1954; Lelijveld \& Kortmann, 1970). These assays are complicated with many procedures before the drug is determined. Amodiaquine is detected by the fluorometric method of Trenholme et al. (1974) whereas quinine is detected by the use of the MayerTanret reagent. Pyrimethamine has for a long time presented detection difficulties with qualitative methods as at recommended dosages the plasma and urine levels are very low. Gas chromatography (GC), higher performance liquid chromatography (HPLC) or mass spectrometry (MS) have been recommended for its detection (Jones \& King, 1968).

The concentration of sulfadoxine or sulfanilamide in urine and blood is determined by a colorimetric technique (Bratton \& Marshall, 1939). In this technique, trichloroacetic acid filtrate of sample is mixed in a stepwise fashion with sodium nitrite, ammonium sulfamate and N-(1-naphthyl) ethylenediamine to yield a coloured dye the intensity of which is read at $545 \mathrm{~nm}$. Smith et al. (1945) modified this procedure by producing a cadmium sulfate filtrate of plasma or urine that was first acidified by 0.2 volume of $1.2 \mathrm{~N}$ hydrochloric acid prior to the sequential steps noted above. It was several decades later that it was realized that chloride and temperature were critical for the colour development in these assays (Waugh, 1974). Nevertheless, fresh preparation of reagents (nitrite and sulfamate), sequential addition of three reagents, timing of which is critical, and temperature dependence of these assays make these techniques cumbersome. Some simplification of the technique was obtained when Brun (1951) created a two-step procedure. In this technique plasma protein is precipitated by Somogyi's zinc sulfate and sodium hydroxide followed by addition of $p$-dimethylaminobenzaldehyde (Ehrlich's reagent) in acidic alcohol to form a yellow dye which is read at $465 \mathrm{~nm}$ in a colorimeter. However, different analytical procedures are required for high and low plasma concentrations.

Three decades ago, Waugh \& Beall (1974) reported a two-step procedure in which buffered 1.0M dichloroacetate and $0.3 \mathrm{M} p$-toluene sulfonate reagent is used for deproteinization and acidification of the sample; a yellow product is then obtained by adding $57 \%$ ethanolic 1\% p-dimethylaminobenzaldehyde. Even in this assay, blank plasma chromogen ranges from 21\%-73\%, and urea and other sulfonamides containing free $p$-amino radical interferes with the assay.

The TLC techniques developed in our study, is very easy to handle under laboratory conditions. With a lower detection limit of $0.00025 \mathrm{mg} / \mathrm{ml}$ for chloroquine, amodiaquine, quinine and primaquine; $0.0005 \mathrm{mg} / \mathrm{ml}$ for sulfadoxine and $0.001 \mathrm{mg} / \mathrm{ml}$ for 
pyrimethamine the method is sensitive. The TLC method we have developed can be used under field conditions and it does not require expensive consumables compared to HPLC method. Although HPLC methods are able to detect chloroquine, amodiaquine, quinine, primaquine, sulfadoxine and pyrimethamine at levels as low as $0.000001 \mathrm{mg} / \mathrm{ml}$, they can only be performed in sophisticated laboratories with well-trained staff. Despite that HPLC has good chromatographic selectivity, simultaneous determination of chloroquine, amodiaquine, primaquine, quinine, pyrimethamine and sulphadoxine using same mobile phase is not possible as their $\mathrm{pHs}$ require different conditions.

Our findings indicate that the technique enables the detection and quantitation of chloroquine, amodiaquine, quinine, primaquine, sulphadoxine and pyrimethamine. Moreover, its detection limit is very low and more than 10 samples can be analyzed in one run. This simple technique can therefore be suitable for antimalarial drug quality and bioavailability studies that address the role of drug absorption and excretion in malaria chemotherapy. It can also be used to detect types of antimalarial drugs commonly used by people in the community.

The utility of this method can be extended to the quality control of chloroquine, amodiaquine, quinine, primaquine, sulphadoxine and pyrimethamine drugs in the context of the need to carefully monitor drug purity in a tropical climate is high, particularly in situations where there may be doubt about the quality of the primary manufacturer. However, with the current introduction of new first line antimalarial drugs that are taking place in a number of sub-Saharan African countries, more studies needs to be done to address the changes.

\section{Acknowledgements}

Our sincere thanks are due to Messrs Japhet Kimbesa and Jumanne Hamisi for their technical and laboratory assistance. This study received financial and logistic support from the National Institute for Medical Research, Tanzania.

\section{References}

Bratton, A.C. \& Marshall, E.K. (1939) A new coupling component for sulfanilamide determination. Journal of Biological Chemistry 128, 537.

Brodie, B.B., Udenfriend, S., Dill, W. \& Downing, G. (1947) The estimation of basic organic compounds in biological materials. II Estimation of fluorescent compounds. Journal of Biological Chemistry 168, 311.

Brun, C. (1951) A rapid method for the determination of para-aminohippuric acid in kidney function tests. Journal of Laboratory and Clinical Medicine. 37, 955-958.

Desage, M., Soubeyrand J., Soun A., Brazier J.L. \& Georges Y. (1984) Automated theophylline assay using gas chromatography and a mass selective detector. Journal of Chromatography 336, 285291.

Devarajan P.V., Sule P.N. \& Parmar D.V. (1999) Highperformance thin-layer chromatographic determination of theophylline in plasma. Journal of Chromatography B. Biomedical Sciences and Applications 736, 289-293.

Hay, S. I., Guerra, C. A., Tatem, A. J., Noor, A. M. \& Snow, R. W. (2004). The global distribution and population at risk of malaria: past, present and future. Lancet Infectious Diseases 4, 327-336.

Idowu, O.A., Apalara, S.B. \& Lasisi, A.A. (2006) Assessment of quality of chloroquine tablets sold by drug vendors in Abeokuta, Nigeria. Tanzania Health Research Bulletin 8, 45-46.

Jones, C.R. \& King, L.A. (1968) Detection and fluorescent measurement of pyrimethamine in urine. Biochemical Medicine 2, 251.

Lelijveld, J. \& Kortmann, H. (1970) The eosin colour test of Dill and Glazko: a simple field test to detect chloroquine in urine. Bulletin of the World Health Organization 42, 477.

Li Wan Po, A. (2001) Too much, too little, or none at all: dealing with substandard and fake drugs. Lancet 357, 1904.

Minzi, O.M.S., Moshi, M.J., Hipolite, D., Massele, A.Y., Tomson, G. Ericsson, Ö . \& Gustafsson, L.L. (2003) Evaluation of the quality of amodiaquine and sulphadoxine/pyrimethamine tablets sold by private wholesale pharmacies in Dar es Salaam, Tanzania. Journal of Clinical Pharmacy and Therapeutics 28, 117.

Ogwal-Okeng, J.W., Okello, D.O. \& Odyek, O. (1998) Quality of oral and parenteral chloroquine in Kampala. East African Medical Journal, 75, 692694.

Pokrajac, M. \& Varagic, V.M. (1983) Spectrodensitometric determination of theophylline in plasma. Acta Pharmaceutica Jugoslavica 33, 23-27. 
Rimoy, G.R., Moshi, M.J. \& Massele, A.Y. (2002) Comparative bioavailability of oral sugar-coated and plain formulation of chloroquine phosphate marketed in Tanzania. Tropical Doctor 32, 1517.

Shakoor, O., Taylor, R.B. \& Behrens, R.H. (1997) Assessment of the incidence of substandard drugs in developing countries. Tropical Medicine and International Health 2, 839-845.

Smith, H.W., Finkelstein, L., Aliminosa, L., Crawford, B. \& Graber, M. (1945) The renal clearances of substituted hippuric acid derivatives and other aromatic acids in dog and man. Journal of Clinical Investigation 24, 388-404.

Snow, R.W., Craig, M.H., Deichmann, U. \& le Sueur, D. (1999) A continental risk map for malaria mortality among African children. Parasitology Today 15, 99-104.

Stenson, B., Lindgren, B.H., Synhakhang, L. \& Tomson, G. (1998) The quality of drugs in private pharmacies in the Lao People's
Democratic Republic. International Journal of Risk and Safety in Medicine, 11, 243-249. Trenholme G.M., Williams R.L., Patterson E.C., Frischer H., Carson P.E., Rieckmann K.H. (1974) A method for determination of amodiaquine. Bulletin of the World Health Organization 51, 431.

Waugh, W.H. (1974) Effect of chloride on paminohippurate analyses by the BrattonMarshall method. Journal of Applied Physiology 37, 752-755.

Waugh, W. H. \& P. T. Beall (1974) Simplified measurement of p-aminohippurate and other arylamines in plasma and urine. Kidney International 5, 429-436.

WHO (2003) Worldwide Malaria Distribution in 2002.Public Health Mapping Group, World Health Organization, Geneva.

Wilson, T. \& Edeson, J.F.B. (1954) Studies on the chemotherapy of Malaria. III. The treatment of acute malaria with chloroquine. Medical Journal of Malaya 9, 115. 